\title{
Subjective ratings of sleep quality and anxiety after placebo, drug and a food drink
}

\author{
Kirstine Adam \\ B.Sc.
}

\author{
LiISI ADAMSON \\ M.Sc.
}

\section{Summary}

Ten subjects (mean age 57 years) took part in a crossover study between a food drink and nitrazepam $5 \mathrm{mg}$. They rated their anxiety and sleep quality. On half the sleep laboratory nights during baseline periods subjects were given an inert pill which they were told would improve sleep. A comparison was made between the six pill and six non-pill nights for each subject. Subjective ratings revealed no significant difference attributable to the inert pill. Sleep quality was rated to have been improved during both late drug and early food drink administration. On early drug withdrawal sleep quality was rated worse than baseline.

\section{Introduction}

There have been very few studies of the effect of placebo on sleep, and yet this is an important consideration when a treatment is administered whose nature cannot be disguised, and with which subjects may associate an effect. In a study comparing placebo, flurazepam and no treatment, Kales et al. (1971) demonstrated no effect of placebo on sleep induction, maintenance, stages or on subjective assessment of sleep quality. Davis and Hartmann (1973) recorded subjects electrophysiologically and found no significant difference in total sleep time and sleep onset latency between the means of three placebo and three treatment nights. In a later experiment, comparing the EEG recordings of subjects on placebo for 28 days with a preceding baseline period, Hartmann and Cravens (1973) believed they had found a rather tenuous connection between placebo administration and an increased amount of REM sleep which continued into early withdrawal from placebo. The present study differs from those mentioned above in that our subjects were told that the inert pill would have a beneficial effect on their sleep and hence more specifically investigated the power of suggestion.

\section{Methods}

Ten healthy subjects aged 41-62 years (mean 57쇼 years) took part in a cross-over study between a foodo drink and nitrazepam $5 \mathrm{mg}$.

Subjects attended the sleep laboratory in pairs differing from each other for the experimental? condition. Each subject slept in quiet and comfort-⿳亠丷厂巾 able conditions on a total of 58 nights spread over 38 weeks according to the experimental design \&nc Table 1.

TABLE 1. The experimental design used

\begin{tabular}{|c|c|}
\hline Week No. & Treatment \\
\hline 1 and 2 & 2 Adaptation nights \\
\hline 5 and 6 & $\begin{array}{l}6 \text { Baseline nights } \\
1 \text { Adaptation night } \\
6 \text { Early treatment nights }\end{array}$ \\
\hline $\begin{array}{r}7,8,9 \text { and } 10 \\
11 \text { and } 12\end{array}$ & $\begin{array}{l}\text { Treatment continued at home } \\
1 \text { Adaptation night } \\
6 \text { Late treatment nights }\end{array}$ \\
\hline $\begin{array}{l}13 \text { and } 14 \\
15 \text { and } 16\end{array}$ & $\begin{array}{l}\text { Treatment continued at home } \\
1 \text { Adaptation night } \\
6 \text { Withdrawal nights }\end{array}$ \\
\hline
\end{tabular}

Six weeks later, subjects repeated the above schedule on the alternative treatment. Treatments were administered about $30 \mathrm{~min}$ before lights out (approximately 11.30 p.m. to 7.30 a.m.).

Subjects rated their own sleep quality in the $N$ morning and in the evening rated their daytime $N$ anxiety using visual analogue scales $(0-100 \mathrm{~mm}) \stackrel{\mathrm{C}}{\mathrm{N}}$ where sleep quality ranges from 'worst' to 'best' and ${ }_{\sigma}^{\omega}$ anxiety from 'terrible agitation' to 'imperturbable tranquillity'.

On half the baseline nights and in balanced order $\stackrel{\overparen{D}}{\mathscr{D}}$ each subject was given a pink placebo pill. They were ${ }_{\tau}^{+}$ told that these would 'help make your sleep more ${ }^{\circ}$ restful without causing any hangover'. The food $\overrightarrow{\mathbb{D}}$ 
drink was made with $32 \mathrm{~g}$ of Horlicks powder mixed with $250 \mathrm{ml}$ of hot milk. The drug and the food drink were each taken for 10 weeks by every subject.

\section{Results}

Ignoring the subjective ratings collected on the adaptation nights, each of the ten subjects had a total of twelve baseline nights (six pill and six nonpill) and six laboratory nights for each of the other experimental conditions.

Friedman's analysis of variance (Siegel, 1956) of the subjective ratings from both baseline periods demonstrated that when the inert pill had been taken the night before neither sleep quality improved $\left(\chi r^{2}=3.45\right.$, d.f. $=3$, n.s.) (Table 2$)$ nor anxiety altered $\left(\chi r^{2}=1 \cdot 32\right.$, d.f. $=3$, n.s.) (Table 4).

\section{TABLE 2}

\begin{tabular}{lc}
\hline Subjective sleep quality & mean \pm s.e. (in mm) \\
\hline Mean baseline: pill & $45 \cdot 6 \pm 2 \cdot 4$ \\
non-pill & $49 \cdot 2 \pm 3 \cdot 3$ n.s. \\
& $47 \cdot 4 \pm 2 \cdot 6$ \\
\hline
\end{tabular}

TABLE 3

\begin{tabular}{lc}
\hline Subjective sleep quality & mean \pm s.e. (in mm) \\
\hline Mean baseline & $47 \cdot 4 \pm 2 \cdot 6$ \\
Early drug & $50 \cdot 1 \pm 2 \cdot 9$ \\
Late drug & $53 \cdot 0 \pm 3 \cdot 0 \dagger$ \\
Drug early withdrawal & $39 \cdot 9 \pm 3 \cdot 0^{*}$ \\
Early food drink & $50 \cdot 7 \pm 2 \cdot 7 \dagger$ \\
Late food drink & $49 \cdot 8 \pm 2 \cdot 3$ \\
Food drink early withdrawal & $50 \cdot 7 \pm 2 \cdot 6$ \\
\hline
\end{tabular}

* significantly lower than baseline at $P<0.05$ level (1-tailed test)

$\dagger$ significantly greater than baseline at $P<0.025$ level (1-tailed test)

Sleep quality was rated to have been improved during both the late drug $(t=2.28, P<0.025,1-$ tailed) and early food drink ( $t=2.63, P<0.025$, 1 -tailed) administration, when correlated $t$-tests were used to compare them with baseline (Table 2).

A difference between subjective ratings of sleep quality was seen when comparing the baseline mean
TABLE 4. Subjective anxiety ratings for the day before and the day following a night spent at the sleep laboratory

\begin{tabular}{cc}
\hline & Mean \pm s.e. (in mm) \\
\hline Before & \\
Mean baseline: pill & $51 \cdot 8 \pm 1 \cdot 8$ \\
non-pill & $52 \cdot 9 \pm 2 \cdot 1$ \\
After & \\
Mean baseline: & pill \\
non-pill & $52 \cdot 7 \pm 1.9$ \\
& $51 \cdot 2 \pm 1 \cdot 7$ \\
\hline
\end{tabular}

with early withdrawal (laboratory nights 1, 2 and 3) from the drug, i.e. sleep being rated worse after drug withdrawal $(t=1 \cdot 88, P<0.05,1$-tailed).

No significant differences were found between the baseline anxiety rating and any subsequent treatment.

\section{Discussion}

Any experiment which sets out to investigate the value of a treatment whose identity cannot be concealed is faced with the problem of how big a part suggestion may play in the results. In this experiment subjects were specifically told that their sleep would be improved and yet this was not reflected in the subjective ratings. The results of the EEG sleep recordings made on the nights when subjects attended the laboratory appear also unaffected by placebo but will be reported at a later date.

\section{References}

Davis, D. \& HartmanN, E. (1973) A comparison of the effects of an OTC sleeping medication, placebo and no medication on human sleep. Sleep Research, 2, 51.

Hartmann, E. \& Cravens, J. (1973) The effects of long term administration of psychotropic drugs on human sleep. I. Methodology and the effects of placebo. Psychopharmacologia, Berlin, 33, 153.

Kales, J., Kales, A., Bixler, E.O. \& Slye, E.S. (1971) Effects of placebo and flurazepam on sleep patterns in insomniac subjects. Clinical Pharmacology and Therapeutics, 12, 691.

SIEGEL, S. (1956) Nonparametric Statistics for the Behavioral Sciences. New York, McGraw-Hill. 